\title{
Spurious regression in nonstationary panels with cross-unit cointegration
}

Citation for published version (APA):

Urbain, J. R. Y. J., \& Westerlund, J. (2006). Spurious regression in nonstationary panels with cross-unit cointegration. METEOR, Maastricht University School of Business and Economics. METEOR Research Memorandum No. 057 https://doi.org/10.26481/umamet.2006057

Document status and date:

Published: 01/01/2006

DOI:

10.26481/umamet.2006057

Document Version:

Publisher's PDF, also known as Version of record

\section{Please check the document version of this publication:}

- A submitted manuscript is the version of the article upon submission and before peer-review. There can be important differences between the submitted version and the official published version of record.

People interested in the research are advised to contact the author for the final version of the publication, or visit the DOI to the publisher's website.

- The final author version and the galley proof are versions of the publication after peer review.

- The final published version features the final layout of the paper including the volume, issue and page numbers.

Link to publication

\footnotetext{
General rights rights.

- You may freely distribute the URL identifying the publication in the public portal. please follow below link for the End User Agreement:

www.umlib.nl/taverne-license

Take down policy

If you believe that this document breaches copyright please contact us at:

repository@maastrichtuniversity.nl

providing details and we will investigate your claim.
}

Copyright and moral rights for the publications made accessible in the public portal are retained by the authors and/or other copyright owners and it is a condition of accessing publications that users recognise and abide by the legal requirements associated with these

- Users may download and print one copy of any publication from the public portal for the purpose of private study or research.

- You may not further distribute the material or use it for any profit-making activity or commercial gain

If the publication is distributed under the terms of Article $25 \mathrm{fa}$ of the Dutch Copyright Act, indicated by the "Taverne" license above, 
Jean-Pierre Urbain, Joakim Westerlund

Spurious Regression in Nonstationary Panels with Cross-Unit Cointegration

$\mathrm{RM} / 06 / 057$

JEL code : C13, C33

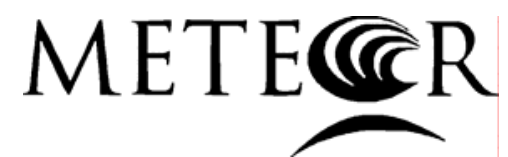

Maastricht research school of Economics of TEchnology and ORganizations

Universiteit Maastricht

Faculty of Economics and Business Administration P.O. Box 616

NL - 6200 MD Maastricht

phone : :++31433883830

fax $\quad$ : ++31433884873 



\title{
Spurious Regression in Nonstationary Panels with Cross-Unit Cointegration*
}

\author{
Jean-Pierre Urbain ${ }^{\dagger}$ and Joakim Westerlund ${ }^{\ddagger}$
}

December 14, 2006

\begin{abstract}
This paper illustrates analytically the effects of cross-unit cointegration using as an example the conventional pooled least squares estimate in the spurious panel regression case. The results suggest that the usual result of asymptotic normality depends critically on the absence of cross-unit cointegration.
\end{abstract}

JEL Classification: C13; C33.

Keywords: Panel Cointegration; Spurious Regression; Cross-Unit Cointegration; Cross-Section Dependence.

\section{Introduction}

The use of nonstationary panel data techniques to infer both spurious and cointegrated regressions has basically exploded during the last couple of years. The main reason for this being the more powerful and straightforward asymptotic results based on pooling across a large cross-section of independent units. In fact, as shown by Phillips and Moon (1999), since this independence effectively works by smoothing out the usual unit root dependency for each unit, normal inference is usually possible, even in the usually so difficult spurious regression case.

\footnotetext{
*A preliminary version of the paper was presented at the Conference on Common Feature in Maastricht, at Ente "Luigi Einaudi" in Rome, ESEM2004 in Madrid and at the Econometric Seminar in Rotterdam. The author wants to thank Christian Gengenbach, Stéphane Grégoir, Richard Paap, Franco Peracchi and Fabio Busetti for helpful comments and suggestions. The second author would also like to thank the Maastricht Research School of Economics of Technology and Organizations for its hospitality during a visit at the Department of Quantitative Economics at the University of Maastricht, where a part of this paper was written. Thank you also to the Jan Wallander and Tom Hedelius Foundation for financial support under research grant number W2006-0068:1. The usual disclaimer applies.

${ }^{\dagger}$ Corresponding author: Department of Quantitative Economics, Universiteit Maastricht, P.O. Box 616, 6200 MD Maastricht, The Netherlands. Telephone: +31 43388 3660; Fax: +31 43388 48 74; E-mail address: j.urbain@ke.unimaas.nl

$\ddagger$ Department of Economics, Lund University, P.O.Box 7082, S-220 07 Lund, Sweden. Telephone: +46 46222 8670; Fax: +46 46222 4118; E-mail address: joakim.westerlund@nek.lu.se.
} 
However, as argued by Banerjee at al. (2006), assuming independence in this way is usually not warranted, especially when considering macroeconomic or financial data with strong intra-economic linkages. In particular, by using simulation methods, they show that the presence of cross-unit cointegration, a reasonable assumption in most applications, can have quite drastic effects on inference.

In this paper, we complement analytically the simulation results of Banerjee at al. (2006) taking as an example the pooled least squares slope estimator in the simple bivariate case. ${ }^{1}$ We consider two possibilities, one is when the cointegration occurs across the whole panel, while the other is when the cointegration occurs within groups that are otherwise independent of each other, which seems like a reasonable scenario when studying for example convergence clubs. In both cases, it is shown that the presence of cross-unit cointegration in both the dependent and independent variables leads to statistics that diverge with the size of the crosssection. On the other hand, if at least one of the variables does not cointegrate across units, then normality is again possible, with the center of the distribution located at the long-run average regression coefficient. For the case with cointegration within groups, this naturally leads to the definition of a long-run average group coefficient.

The next two sections present our main findings, while Section 4 concludes. All proofs are regelated to the appendix.

\section{Panel common unit roots}

Suppose that $y_{i t}$ and $x_{i t}$ are two a scalar variables such that

$$
x_{i t}=\lambda_{x i} f_{x t}+\delta_{x i} e_{x i t}+u_{x i t} \text { and } y_{i t}=\lambda_{y i} f_{y t}+\delta_{y i} e_{y i t}+u_{y i t},
$$

where $t=1, \ldots, T$ and $i=1, \ldots, N$ indexes the time series and cross-sectional units, respectively. Note that while the first term on the right-hand side of these equations are common across $i$, the second is not. The parameters $\lambda_{x i}, \delta_{x i}, \lambda_{y i}$ and $\delta_{y i}$ are assumed to be mutually independent, and randomly distributed across $i$ with expected values $\lambda_{x}, \delta_{x}, \lambda_{y}$ and $\delta_{y}$, respectively. We further assume that the disturbances $u_{x i t}$ and $u_{y i t}$ are stationary processes, while the remaining righthand side variables in (1) are pure unit root processes that satisfy the following invariance principles as $T \rightarrow \infty$ for each $i$

$$
\frac{1}{\sqrt{T}}\left[\begin{array}{l}
f_{x t} \\
f_{y t}
\end{array}\right] \Rightarrow\left[\begin{array}{c}
B_{x} \\
B_{y}
\end{array}\right] \text { and } \frac{1}{\sqrt{T}}\left[\begin{array}{l}
e_{x i t} \\
e_{y i t}
\end{array}\right] \Rightarrow\left[\begin{array}{c}
B_{x i} \\
B_{y i}
\end{array}\right]
$$

where $\Rightarrow$ signifies weak convergence. The vectors of common and idiosyncratic Brownian motions, $B$ and $B_{i}$ say, are assume to be independent with covariance matrices $\Omega^{f}$ and $\Omega_{i}^{e}$, respectively, where $\Omega_{i}^{e}$ is a random matrix with expectation

\footnotetext{
${ }^{1}$ This work is related to that of Gengenbach et al. (2006). However, while they focus specifically on the case when testing for cointegration, our focus is more conceptual, and our interest in the least squares slope estimate is just for illustration.
} 
$\Omega^{e}$. All variables and random parameters indexed by $i$ are independent along the cross-sectional dimension.

Although very simple, as we shall see, this data generating process yields significant insight. In particular, note how (1) nests a variety of spurious regression cases both with and without cross-unit cointegration, depending on the values taken by $\lambda_{x i}, \delta_{x i}, \lambda_{y i}$ and $\delta_{y i} \cdot{ }^{2}$ In fact, it is not difficult to see that (1) is actually a system of two Bai and Ng (2004) factor models, one for $x_{i t}$ and one for $y_{i t}$. Define

$$
\widehat{\beta}=\left(\sum_{i=1}^{N} \sum_{t=1}^{T} x_{i t} y_{i t}\right) /\left(\sum_{i=1}^{N} \sum_{t=1}^{T} x_{i t}^{2}\right) .
$$

The objective of this paper is to show how $\widehat{\beta}$, the conventional pooled least squares slope estimator in a regression of $y_{i t}$ on $x_{i t}$, behaves in this context.

Let us define the following two quantities

$$
\begin{aligned}
Q_{x x} & =\lambda_{x}^{2}\left(\int B_{x}^{2}\right)+\frac{1}{2} \delta_{x}^{2} \Omega_{x x}^{e} \\
U_{x y} & =\frac{1}{6}\left(\lambda_{x}^{2} \delta_{y}^{2} \Omega_{x x}^{f} \Omega_{y y}^{e}+\lambda_{y}^{2} \delta_{x}^{2} \Omega_{y y}^{f} \Omega_{x x}^{e}+\delta_{y}^{2} \delta_{x}^{2} \Omega_{y y}^{e} \Omega_{x x}^{e}\right) \\
& +\frac{1}{2} \lambda_{y} \lambda_{x} \delta_{y} \delta_{x} \Omega_{x y}^{f} \Omega_{x y}^{e} .
\end{aligned}
$$

Given $Q_{x x}$ and $U_{x y}$, if we let $\rightarrow p$ signify convergence in probability, then the asymptotic distribution of $\widehat{\beta}$ can be summarized in the following way.

Theorem 1. Under the assumptions laid out above, as $N, T \rightarrow \infty$

(a) $\widehat{\beta} \rightarrow p \frac{1}{Q_{x x}}\left(\lambda_{y} \lambda_{x} \int B_{y} B_{x}+\frac{1}{2} \delta_{x} \delta_{y} \Omega_{x y}^{e}\right)$

(b) $\quad \sqrt{N} \widehat{\beta}-\sqrt{N} \frac{1}{Q_{x x}}\left(\lambda_{y} \lambda_{x} \int B_{y} B_{x}+\frac{1}{2} \delta_{x} \delta_{y} \Omega_{x y}^{e}\right) \Rightarrow N\left(0, \frac{1}{Q_{x x}^{2}} U_{x y}\right)$

Note how Theorem 1 expresses the asymptotic distribution of $\widehat{\beta}$ in terms of the parameters of (1). This is very instructive.

Firstly, note that the mean of the distribution depends critically on the common components of $x_{i t}$ and $y_{i t}$. In particular, note that if $\lambda_{x}$ is zero, so that only $y_{i t}$ has a common component, then $\sqrt{N} \widehat{\beta}$ converges to a normal variate with mean $\delta_{y} \Omega_{x y}^{e} / \delta_{x} \Omega_{x x}^{e}$, which is the long-run average regression coefficient derived by Phillips and Moon (1999) in the cross-sectionally independent case. On the other hand, if $\lambda_{x}$ and $\lambda_{y}$ are both nonzero, then $\widehat{\beta}$ is no longer consistent for $\delta_{y} \Omega_{x y}^{e} / \delta_{x} \Omega_{x x}^{e}$, and in fact diverges as $N$ grows. This suggests that much of the empirical work based on the pooled least squares estimator in nonstationary panel data with a possible common factor structure needs to be reevaluated, see for example Coakley et al. (2005).

\footnotetext{
${ }^{2}$ The case with cointegration between $y_{i t}$ and $x_{i t}$ at is also covered, and amounts for example to setting $\lambda_{x i}$ and $\lambda_{y i}$ to zero for all $i$ while imposing equality or proportionality of the idiosyncratic unit roots $e_{x i t}$ and $e_{x i t}$.
} 
This clearly illustrates the importance of the common components, both for inferential and cointegration testing purposes. For example, with both $y_{i t}$ and $x_{i t}$ affected, the asymptotic distribution of $\sqrt{N} \widehat{\beta}$ is no longer normal, but dependent on Brownian motion, which makes it look more like something that one would expect to see in the conventional time series case. Similarly, it is not difficult to see how tests for the absence of cointegration based on the consistency of $\widehat{\beta}$, such as those of Kao (1999), become invalid in this case.

Secondly, the variance of the asymptotic distribution of $\sqrt{N} \widehat{\beta}$ depends on both the idiosyncratic and common components. However, note that if there are no common components, then the variance reduces to $2 \delta_{y}^{2} \Omega_{y y}^{e} / 3$, which is likely to be smaller than for the case with common components, and it is definitely smaller than $2\left(\lambda_{y}^{2} \Omega_{y y}^{f}+\delta_{y}^{2} \Omega_{y y}^{e}\right) / 3$, the variance when $\lambda_{x}$ is zero. Hence, the presence of the common components affects the asymptotic distribution of $\sqrt{N} \widehat{\beta}$ by increasing its variance.

\section{Group specific unit roots}

Next, we examine the case with group specific common unit roots. Specifically, suppose that there are $M$ groups with $K$ units in each, and let $f_{x j t}$ be the common unit root component of $x_{i t}$ for group $j=1, \ldots, K$ containing the units $i=1+$ $(j-1) K, \ldots, j K$. The group specific common component of $y_{i t}$ is constructed in the same way, and is denoted $f_{y j t}$. Let $B_{x j}$ and $B_{y j}$ be the Brownian motions associated with $f_{x j t}$ and $f_{y j t}$, and assume that these have covariance $\Omega_{j}^{f}$ and that they are independent across $j$.

In view of Theorem 1 , it is not difficult to see that as $N, T \rightarrow \infty$ with $M$ fixed

$$
\widehat{\beta} \rightarrow p\left(\lambda_{y} \lambda_{x} \frac{1}{M} \sum_{j=1}^{M} \int B_{y j} B_{x j}+\frac{1}{2} \delta_{x} \delta_{y} \Omega_{x y}^{e}\right) /\left(\lambda_{x}^{2} \frac{1}{M} \sum_{j=1}^{M} \int B_{x j}^{2}+\frac{1}{2} \delta_{x}^{2} \Omega_{x x}^{e}\right) .
$$

By contrast, if $M$ is permitted to grow with $N$, then we get

$$
\widehat{\beta} \rightarrow p\left(\lambda_{y} \lambda_{x} \Omega_{x y}^{f}+\delta_{x} \delta_{y} \Omega_{x y}^{e}\right) /\left(\lambda_{x}^{2} \Omega_{x x}^{f}+\delta_{x}^{2} \Omega_{x x}^{e}\right),
$$

where $\Omega^{f}$ is the expected value of $\Omega_{j}^{f}$. This second result is very interesting. Specifically, suppose that $\delta_{x}$ is zero so that $x_{i t}$ has no idiosyncratic unit root, then the probability limit of $\widehat{\beta}$ reduces to $\lambda_{y} \Omega_{x y}^{f} / \lambda_{x} \Omega_{x x}^{f}$, which might be thought of as a long-run average group coefficient. Thus, if the number of groups are permitted to grow with $N$, then we end up with something that is very similar to what we had earlier in the case with panel common unit roots. This seems very reasonable since in this case the group essentially takes the role of the individual unit. Moreover, as in Section 2, it is possible to show that if $M$ is permitted to grow with $N$ and $T$, then $\sqrt{N} \widehat{\beta}$ is asymptotically normal. 


\section{Concluding remarks}

It is now well-known that the conventional assumption of independent cross-sections is very hard to maintain when conducting inference in nonstationary panels.

In this paper, we study the effects of cross-unit cointegration taking as an example the pooled least squares estimator in the spurious regression case. We consider both the case when the cointegration takes place across the panel as a whole, and when it takes place within groups. Our findings suggest that the presence of crossunit cointegration can have dramatic effects for the usual asymptotic results based on cross-section independence, and that the consistency and asymptotic normality of the pooled least squares estimator may even be lost. These results have important implications, not only for theoretical, but also for applied work. Take for example the study of Coakley et al. (2005), in which the authors seek to infer purchasing power parity using pooled least squares methods in the presence of common factors. Our results indicate that this type of analysis can be potentially very deceptive.

As a final note, although the simplicity of the data generating process used in this paper naturally raises some concerns, we would like to stress that most assumptions are only for ease of exposure, and can in principle be relaxed without affecting the main conclusions. For example, it can be easily generalized to accommodate deterministic intercept, trend terms and additional dynamics.

\section{References}

Bai, J., and S. Ng (2004). A Panic Attack on Unit Roots and Cointegration. Econometrica 72, 1127-1177.

Banerjee, A., M. Marcellino and C. Osbat (2004). Some Cautions on the use of Panel Methods for Integrated Series of Macroeconomic Data. Econometrics Journal 7, 322-340.

Coakley, J., R. P. Flood, A. M. Fuertes and M. P. Taylor (2005). Purchasing Power Parity and the Theory of General Relativity: The First Tests. Journal of International Money and Finance 24, 293-316.

Gengenbach, C., F. C. Palm and J-P. Urbain (2006). Panel Cointegration Testing in the Presence of Common Factors. Oxford Bulletin of Economics and Statistics 68, 683-719.

Kao, C. (1999). Spurious Regression and Residual-Based Tests for Cointegration in Panel Data. Journal of Econometrics 90, 1-44.

Phillips, P. C. B., and H. R. Moon (1999). Linear Regression Limit Theory of Nonstationary Panel Data. Econometrica 67, 1057-1111. 


\section{Mathematical appendix}

In this appendix, Theorem 1 is proven. For brevity, only necessary details are provided. Unreported results can be obtained from the corresponding author upon request.

\section{Proof of Theorem 1.}

Consider (a). The least squares estimator of $\beta$ can be written as

$$
\sqrt{N} \widehat{\beta}=\left(\frac{1}{N T^{2}} \sum_{i=1}^{N} \sum_{t=1}^{T} x_{i t}^{2}\right)^{-1} \frac{1}{\sqrt{N} T^{2}} \sum_{i=1}^{N} \sum_{t=1}^{T} x_{i t} y_{i t} .
$$

Consider the denominator, whose limit as $N, T \rightarrow \infty$ is given by

$$
\begin{aligned}
\frac{1}{N T^{2}} \sum_{i=1}^{N} \sum_{t=1}^{T} x_{i t}^{2} & =\lambda_{x i}^{2} \frac{1}{T^{2}} \sum_{t=1}^{T} f_{x t}^{2}+\delta_{x i}^{2} \frac{1}{N T^{2}} \sum_{i=1}^{N} \sum_{t=1}^{T} e_{x i t}^{2} \\
& +2 \lambda_{x i} \delta_{x i} \frac{1}{N T^{2}} \sum_{i=1}^{N} \sum_{t=1}^{T} f_{x t} e_{x i t}+O_{p}\left(T^{-1}\right) \\
& \rightarrow p \\
& \lambda_{x}^{2}\left(\int B_{x}^{2}\right)+\delta_{x}^{2} E\left(\int B_{i x}^{2}\right)+2 \lambda_{x} \delta_{x} E\left(\int B_{x} B_{i x}\right) \\
& =\lambda_{x}^{2}\left(\int B_{x}^{2}\right)+\frac{1}{2} \delta_{x}^{2} \Omega_{x x}^{e},
\end{aligned}
$$

where the last equality follows from the independence of $B_{x}$ and $B_{i x}$, and the moments of Brownian motion.

Similarly, for the numerator, we have

$$
\begin{aligned}
\frac{1}{\sqrt{N} T^{2}} \sum_{i=1}^{N} \sum_{t=1}^{T} x_{i t} y_{i t} & =\sqrt{N} \lambda_{x i} \lambda_{y i} \frac{1}{T^{2}} \sum_{t=1}^{T} f_{x t} f_{y t}+\lambda_{x i} \delta_{y i} \frac{1}{\sqrt{N} T^{2}} \sum_{i=1}^{N} \sum_{t=1}^{T} f_{x t} e_{y i t} \\
& +\lambda_{y i} \delta_{x i} \frac{1}{\sqrt{N} T^{2}} \sum_{i=1}^{N} \sum_{t=1}^{T} f_{y t} e_{x i t} \\
& +\delta_{y i} \delta_{x i} \frac{1}{\sqrt{N} T^{2}} \sum_{i=1}^{N} \sum_{t=1}^{T} e_{y i t} e_{x i t}+O_{p}\left(T^{-1}\right)
\end{aligned}
$$

which has the following limit as $T \rightarrow \infty$

$$
\begin{aligned}
\frac{1}{\sqrt{N} T^{2}} & \sum_{i=1}^{N} \sum_{t=1}^{T} x_{i t} y_{i t} \Rightarrow \sqrt{N}\left(\lambda_{x i} \lambda_{y i} \int B_{x} B_{y}\right) \\
& +\frac{1}{\sqrt{N}} \sum_{i=1}^{N}\left(\lambda_{x i} \delta_{y i} \int B_{x} B_{y i}+\lambda_{y i} \delta_{x i} \int B_{y} B_{x i}+\delta_{y i} \delta_{x i} \int B_{y i} B_{x i}\right) \\
& =\sqrt{N}\left(\lambda_{x i} \lambda_{y i} \int B_{x} B_{y}\right)+\frac{1}{\sqrt{N}} \sum_{i=1}^{N} U_{i}, \text { say. }
\end{aligned}
$$


Thus, passing $N \rightarrow \infty$, it is clear that

$$
\frac{1}{N T^{2}} \sum_{i=1}^{N} \sum_{t=1}^{T} x_{i t} y_{i t}-\left(\lambda_{x} \lambda_{y} \int B_{x} B_{y}\right)=\frac{1}{N} \sum_{i=1}^{N} U_{i} \rightarrow p \frac{1}{2} \delta_{x} \delta_{y} \Omega_{x y}^{e} .
$$

This establishes (a).

Next, consider (b). By using (a) and the Lindberg-Lévy theorem, as $N, T \rightarrow \infty$

$$
\begin{array}{r}
\frac{1}{\sqrt{N} T^{2}} \sum_{i=1}^{N} \sum_{t=1}^{T} x_{i t} y_{i t}-\sqrt{N}\left(\lambda_{x} \lambda_{y} \int B_{x} B_{y}+\frac{1}{2} \delta_{x} \delta_{y} \Omega_{x y}^{e}\right) \\
\Rightarrow N\left(0, \lim _{N \rightarrow \infty} \frac{1}{N} \sum_{i=1}^{N} E\left(U_{i}^{2}\right)\right)
\end{array}
$$

For the variance, we have

$$
\begin{aligned}
E\left(U_{i}^{2}\right) & =E\left(\left(\lambda_{x} \delta_{y} \int B_{x} B_{y i}+\lambda_{y} \delta_{x} \int B_{y} B_{x i}+\delta_{y} \delta_{x} \int B_{y i} B_{x i}\right)^{2}\right) \\
& =\lambda_{x}^{2} \delta_{y}^{2} E\left(\int B_{x} B_{y i}\right)^{2}+\lambda_{y}^{2} \delta_{x}^{2} E\left(\int B_{y} B_{x i}\right)^{2}+\delta_{y}^{2} \delta_{x}^{2} E\left(\int B_{y i} B_{x i}\right)^{2} \\
& +2 \lambda_{y} \lambda_{x} \delta_{y} \delta_{x} E\left(\int B_{x} B_{y i}\right)\left(\int B_{x i} B_{y}\right) \\
& =\frac{1}{6}\left(\lambda_{x}^{2} \delta_{y}^{2} \Omega_{x x}^{f} \Omega_{y y}^{e}+\lambda_{y}^{2} \delta_{x}^{2} \Omega_{y y}^{f} \Omega_{x x}^{e}+\delta_{y}^{2} \delta_{x}^{2} \Omega_{y y}^{e} \Omega_{x x}^{e}\right) \\
& +\frac{1}{2} \lambda_{y} \lambda_{x} \delta_{y} \delta_{x} \Omega_{x y}^{f} \Omega_{x y}^{e} .
\end{aligned}
$$

where the second equality follows from the fact that all cross-products except the squared ones have expectation zero, while the second follows from the moments of Brownian motion.

Putting everything together, we obtain

$$
\sqrt{N} \widehat{\beta}-\sqrt{N} \frac{1}{Q_{x x}}\left(\lambda_{x} \lambda_{y} \int B_{x} B_{y}+\frac{1}{2} \delta_{x} \delta_{y} \Omega_{x y}^{e}\right) \Rightarrow N\left(0, \frac{1}{Q_{x x}^{2}} U_{x y}\right) .
$$

This completes the proof of (b). 